九州大学学術情報リポジトリ

Kyushu University Institutional Repository

Studies on the Chlorosis Expressed under Low Temperature Condition in Rice, Oryza sativa L. : II. Phenotypic Expression Behaviors

Chuong, Phan Van

Laboratory of Plant Breeding, Faculty of Agriculture, Kyushu University

Omura, Takeshi

Laboratory of Plant Breeding, Faculty of Agriculture, Kyushu University

https://doi.org/10.5109/23710

出版情報: 九州大学大学院農学研究院紀要. 24 (4)，pp. 201-214，1980-02. Kyushu University バージョン：

権利関係 : 


\title{
Studies on the Chlorosis Expressed under Low Temperature Condition in Rice, Oryza sativa L.
}

\section{Phenotypic Expression Behaviors}

\author{
Phan Van Chuong and Takeshi Omura \\ Laboratory of Plant Breeding, Faculty of Agriculture \\ Kyushu University 46-01, Fukuoka 812
}

(Received October 24, 1979)

\begin{abstract}
The expression behaviors of 4 types of low temperature-induced chlorosis in cultivated rice, Oryza sativa $\mathrm{L}$., have been studied. The $15^{\circ} \mathrm{C}$ and $20^{\circ} \mathrm{C}$ can be considered as the critical temperatures to distinguish type I from type 0 and type IV from type III, respectively. When treated at $15^{\circ} \mathrm{C}$ and then transferred to $20^{\circ} \mathrm{C}$, the least duration of $15^{\circ} \mathrm{C}$ treatment for the effective induction of chlorosis varies from type to type of chlorosis: 3 days for type III, 5 days for type II, continuous treatment for type I. The duration around 7 days of $15^{\circ} \mathrm{C}$ treatment was found as the optimum for the classification of chlorosis types. The seedling development stage most sensitive to low temperature coincides with the stage when the coleoptile reaches from $5 \mathrm{~mm}$ to $10 \mathrm{~mm}$ in height and the third leaf just develops from the leaf primordium from $0.3 \mathrm{~mm}$ to $1.4 \mathrm{~mm}$ in the case of HO 1405 . The shift of low temperature treatment from this stage, earlier or later, leads to lessen the effectiveness of the chlorosis induction. Chlorophyll bleaching under high light intensities may be due to the photodestruction of chlorophyll without damage of the chloroplast structure. An extra addition of iron as well as nitrogen into the medium does not affect the chlorophyll yield of the bleached types.
\end{abstract}

\section{INTRODUCTION}

It is known that chlorophyll formation depends on many factors such as temperature, light and nutrituous elements (Walles, 1967). Chlorophyll accumulation is affected drastically by the fluctuation of these three factors.

At high and low temperatures, greening is greatly or totally inhibited and this effect of the temperatures is a local effect, namely only the part of plant affected by the temperatures is influenced in chlorophyll accumulation whereas the other part is not (Lubimenko, 1927). Many mutants sensitive to low temperature were reported in rice by Omura et al. (1977) with 3 kinds of virescent quite different from one another in character manifestation, and in maize by Millerd and McWilliam (1968) with a mutant failing to accumulate chlorophyll at or below $17^{\circ} \mathrm{C}$. Light and temperature are not doubtful in their interaction in the synthesis of chlorophyll (McWilliam and Naylor, 1967). Hitaka (1976) reported the effects of the light intensity and the temperature along with other factors on the occurrence of chlorosis at the stage of seedling emergence after germination and at the greening stage of the rice seed- 
lings. On the basis of nutrients as factors affecting the chlorophyll formation, high nitrogen concentrations in the media decreased the chlorophyll contents of virescent mutants in rice (Omura et al., 1977). Iron could cure the symptom of chlorosis in rice nurseries by spraying $0.5-1.0 \%$ neutralized iron sulfate (Meelu et al., 1977). Iron chlorosis oat grown in iron-treated soil produced more than 3 times as much top dry matter, crown and root weight as those grown in untreated soil (McDaniel and Dunphy, 1978).

Five types of chlorosis in cultivated rice reported previously (Omura and Chuong, 1979) were subjected to study on their behaviors in phenotypic expression in relation to the effects of temperature, light intensity and nutrients.

\section{MATERIALS AND METHODS}

From the varieties used in the previous study, 104 varieties were chosen to investigate the phenotypic expression behaviors under various temperature conditions. Among them, 5 varieties, HO 1250 (type 0), HO 1329 (type I), HO 1165 (type II), HO 1392 (type III) and HO 1405 (type IV), were chosen as the typical of each chlorosis type and grown under various conditions in order to compare the phenotypic expression. Well matured seeds were sterilized by immersing in $0.2 \%$ Benret solution for 12 hours, then washed by tap water and grown on agar containing modified White's solution as reported by Omura et al. (1977). Unless additional explanation is noticed, seeds were germinated at $30^{\circ} \mathrm{C}$ in darkness for 3 days then transferred to controlled cabinet set at proper temperature and continuously illuminated by fluorescent lamps with a light intensity of about 2000 lux.

Chlorophyll was extracted from the fully expanded third leaf of the young seedlings by $80 \%$ acetone. Two or more leaves depending on the degree of chlorosis were used as sample for chlorophyll extraction to minimize the error of spectrum absorption. Except the investigation of chlorophyll contents of 104 varieties at $17^{\circ} \mathrm{C}$ and $15^{\circ} \mathrm{C}$, the chlorophyll contents in other experiments were calculated by the mean of 2 replications. Spectrophotometric measurements were made by Hitachi 124 spectrophotometer in the experiments 1 and 2 and by Super Scan 3 spectrophotometer in the other experiments. Chlorophyll contents were determined by using the specific absorption coefficient of McKinney (1941).

\section{RESULTS}

\section{Chlorosis expression under various temperature conditions.}

In the previous report (Omura and Chuong, 1979), the authors classified chlorosis into 5 types depending on their phenotypes expressed at $17^{\circ} \mathrm{C}$. However, chlorosis expression was changed with the temperature condition. In order to make clear this point, chlorosis expressions at $15^{\circ} \mathrm{C}, 17^{\circ} \mathrm{C}$ and $20^{\circ} \mathrm{C}$ were investigated. The result is shown in Table 1 . At $15^{\circ} \mathrm{C}$ all of the chlorosis types, except type 0 , turned in white and were severely restricted of 
Table 1. Chlorosis expression under various temperature conditions.

\begin{tabular}{cccc}
\hline & \multicolumn{3}{c}{ Chlorosis expression } \\
\cline { 2 - 4 } Type & $15^{\circ} \mathrm{C}$ & $17^{\circ} \mathrm{C}$ & $20^{\circ} \mathrm{C}$ \\
\hline O & + or $\mathrm{p}$ & + & + \\
I & al or al & or or + & + \\
II & al & - & + \\
III & al & al & + \\
IV & al & al & - \\
\hline
\end{tabular}

Note: $+, \mathrm{p},-, \mathrm{al}^{\prime}$ and al represent normal green, pale, $1 / 2$ upper white, $2 / 3$ upper white and albino-like, respectively.

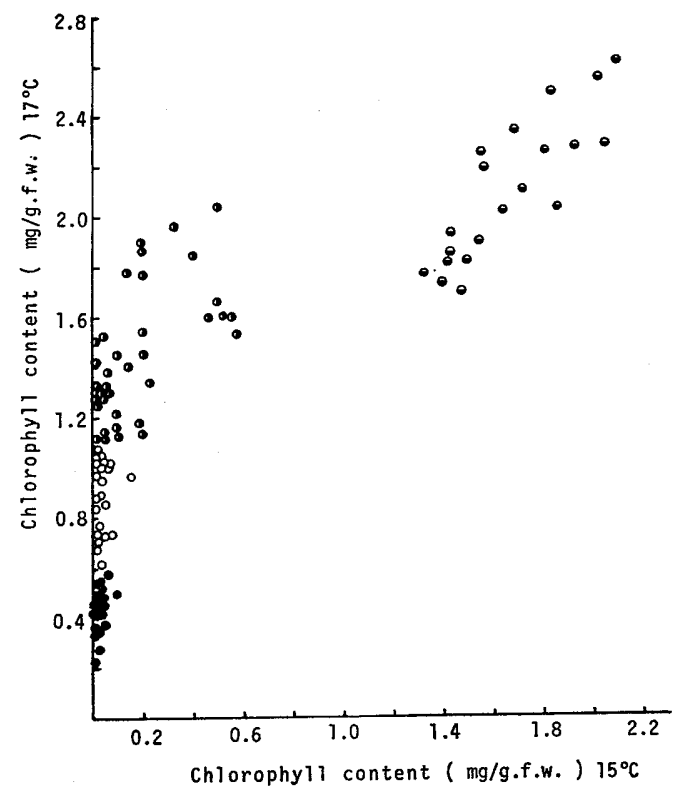

Fig. 1. Chlorophyll content under $17^{\circ} \mathrm{C}$ and $15^{\circ} \mathrm{C}$ conditions. $O$, types III and IV, $O$, type II; $\odot$, type I; $\ominus$, type 0 .

growing. Only type $0 \mathrm{kept}$ in green color or slightly changed to pale green. When grown at $20^{\circ} \mathrm{C}$, all types except type IV turned in green. Only type IV as described previously expressed their chlorotic features of fine stripes or somehow as lichen-colored spots on the third leaf blade.

Some 100 varieties were chosen to investigate the chlorphyll content at $15^{\circ} \mathrm{C}$ and $17^{\circ} \mathrm{C}$. As shown in Fig. 1 , at $17^{\circ} \mathrm{C}$, the chlorophyll contents of types IV and III were from 0 to $0.6 \mathrm{mg} / \mathrm{g}$.f.w, type II from 0.6 to $1.1 \mathrm{mg} / \mathrm{g}$.f.w and types I and 0 above $1.1 \mathrm{mg} / \mathrm{g}$.f.w. At $15^{\circ} \mathrm{C}$, three types II, III and IV almost failed in chlorophyll accumulation and their chlorophyll contents were almost none. The chlorophyll contents of both types I and 0 showed a large variation in contrast with those of types II, III and IV. It is noted that, at $17^{\circ} \mathrm{C}$, there were some difficulties to distinguish type 0 from type I by their conti- 
nuous distribution in chlorophyll content, however, they were separately clustered into two distinct groups at $15^{\circ} \mathrm{C}$.

\section{Least duration of low temprature treatment in inducing chlorosis}

As shown in Table 1, chlorosis types I, II, III and IV expressed the albino-like feature when they were continously treated at $15^{\circ} \mathrm{C}$. Overtreating by low temperature leads to the overlap of different types of chlorosis and makes the classification difficult. Moreover, the continuous treatment of low temperature at $15^{\circ} \mathrm{C}$ wastes time due to the extreme retardation of growth and sometimes leads to the death of the seedlings. Even at $17^{\circ} \mathrm{C}$, the standard temperature for the classification, growth retardation was also remarkable. Therefore, the excess supply of low temperature is not necessary if any alternative measure is available. It is suggested that there are some amounts of low temperature enough effective to induce the chlorosis expression.

To make clear this point, seeds germinated in darkness at $30^{\circ} \mathrm{C}$ for 3 days were transferred to $15^{\circ} \mathrm{C}$ for low temperature treatment. The low temperature treatment was carried out with various durations from 0 to 10 days. After completing the low temperature treatment, seedlings were transferred to $20^{\circ} \mathrm{C}$ for growing. The observation of chlorosis was made on the third leaf blade fully expanded.

Table 2. Least duration of $15^{\circ} \mathrm{C}$ treatment for inducing chlorosis on seedlings germinated at $30^{\circ} \mathrm{C}$ for 3 days.

\begin{tabular}{|c|c|c|c|c|c|c|c|c|c|c|}
\hline \multirow{2}{*}{ Type } & \multicolumn{10}{|c|}{ Day of $15^{\circ} \mathrm{C}$ treatment } \\
\hline & 0 & 2 & 3 & 4 & 5 & 6 & 7 & 8 & 9 & 10 \\
\hline$\left(\mathrm{H} \mathrm{O}^{\mathrm{O}} 1250\right)$ & + & + & + & + & + & + & + & + & + & + \\
\hline ( $\mathrm{H} \mathrm{O}^{\mathrm{l}}$ 1329) & + & + & + & + & + & + & + & + & $\mathrm{p}$ & $\mathrm{p}$ \\
\hline$\left(\mathrm{H} \mathrm{O}^{\text {II }} 1165\right)$ & + & + & $\mathrm{p}$ & $\mathrm{p}$ & - & - & - & $\mathrm{al}^{\prime}$ & $a l^{\prime}$ & $\mathrm{al}^{\prime}$ \\
\hline ( H O 1II $\left.^{\text {III }}\right)$ & + & $\mathbf{p}$ & - & - & $\mathrm{al}^{\prime}$ & $\mathrm{al}^{\prime}$ & $\mathrm{al}^{\prime}$ & $\mathrm{al}^{\prime}$ & al & al \\
\hline (H O 1405) & - & 一 & $\mathrm{al}^{\prime}$ & $\mathrm{al}^{\prime}$ & $\mathrm{al}^{\prime}$ & $\mathrm{al}^{\prime}$ & al & al & al & al \\
\hline
\end{tabular}

Note: Symbols as in Table 1.

As shown in Table 2, types 0 and I did not express any symptom of chlorosis even when the low temperature treatment extended up to 10 days. Type II started to express trace of chlorosis after 5 days of treatment and its phenotype became clear when the treatment duration extended to 6 or 7 days. Types III started to express chlorosis after 3 days of treatment then turned in typical appearance after 5 days, and albino-like after 9 days. Though the chlorosis of type IV appeared at $20^{\circ} \mathrm{C}$, however, it was easier to recognize after 2 days of treatment and became albino-like, the typical phenotype of this type, after 7 days of $15^{\circ} \mathrm{C}$ treatment. A too short duration of low temperature treatment could not reveal the typical feature of each type of chlorosis whereas the overtreatment exceeding 10 days might lead to the overlap of 
chlorosis types, resulting in an uniform of albino-like leaves. A duration of 3 or 4 day-treatment at $15^{\circ} \mathrm{C}$ is enough to induce chlorosis for types II, III and IV, but the phenotypes of chlorosis expressed under such conditions showed somewhat different in the degree of chlorosis from those at $17^{\circ} \mathrm{C}$ condition previously described. When the $15^{\circ} \mathrm{C}$ treatment extented up to around 7 days, the phenotypes of chlorosis types became almost similar to those induced at $17^{\circ} \mathrm{C}$, respectively.

\section{Stage of leaf development most sensitive to low temperature}

To find out the stage of leaf development most sensitive to low temperature in inducing chlorosis, variety HO 1405 (type IV) was used as material. Seeds were pretreated for 0 to 7 days at $30^{\circ} \mathrm{C}$ in darkness then transferred to $15^{\circ} \mathrm{C}$ for 7 days. After completing the low temperature treatment at $15^{\circ} \mathrm{C}$, seedlings were transferred to $20^{\circ} \mathrm{C}$ for growing.

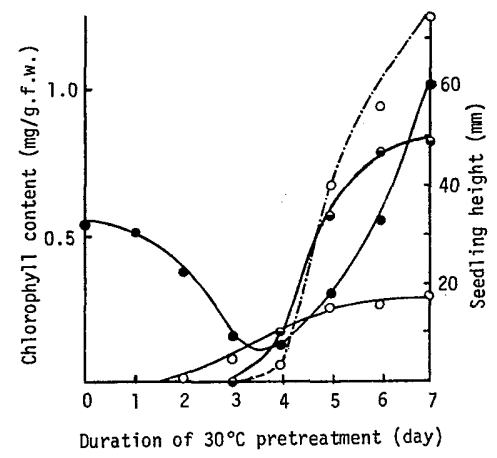

Fig. 2. Leaf development stage most sensitive to low temperature. - Chlorophyll content; $\mathrm{O}-\mathrm{O}$. Coleoptile; $\odot-\ominus$. First leaf; O-.-.-O. Second leaf.

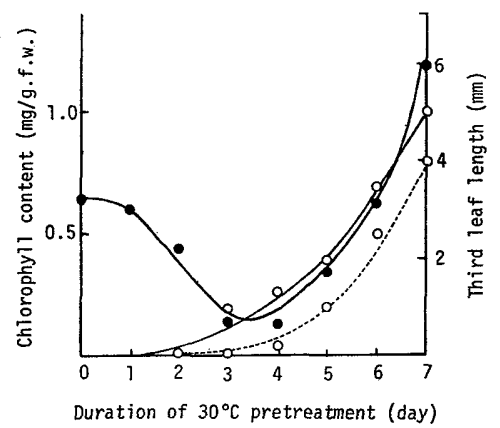

Fig. 3. Third leaf development before and after $15^{\circ} \mathrm{C}$ treatment. Chlorophyll content; $\bigcirc \cdots \cdots .$. , Third leaf height before $15^{\circ} \mathrm{C}$ treatment: $\mathrm{O}-\mathrm{O}$, Third leaf height after $15^{\circ} \mathrm{C}$ treatment.

As shown in Fig. 2, 1 day- and 2 day-pretreated seedlings produced their third leaves with some degree of chlorosis symptom. The seedlings pretrea- 
ted for 3 and 4 days showed clear chlorotic features, especially the 4 day-pretreated seedlings manifested highest degree of chlorosis as albino-like leaves. The 5 day- and 6 day-pretreated seedlings turned in yellow, and almost green in the case of 7 day-pretreated seedlings. Low temperature affected effectively at the stage of 3 or 4 day-pretreated seedlings in inducing chlorosis. Seedlings after 4 days of pretreatment showed the lowest level of chlorophyll content with $0.15 \mathrm{mg} / \mathrm{g} . \mathrm{f} . \mathrm{w}$. The chlorophyll contents of seedlings subjected to $15^{\circ} \mathrm{C}$ treatment without pretreatment and with 7 day-pretreatment were 0.62 and $1.29 \mathrm{mg} / \mathrm{g} . \mathrm{f} . \mathrm{w}$. , respectively.

The development stage of the seedling most sensitive to low temperature coincided with the stage when the coleoptile reached from 5 to $10 \mathrm{~mm}$ high after the $30^{\circ} \mathrm{C}$ pretreatment for 4 days in the dark condition. At this stage, the first leaf was generally still hiden in the coleoptile cavity or sometimes just broke out of the coleoptile. If the first leaf surpassed much higher than the coleoptile, low temperature became less effective in inducing chlorosis (Fig. 2). At the beginning of the stage most sensitive to low temperature, 3 or 4 days of pretreatment, the third leaf was about $0.2 \mathrm{~mm}$ in length and at the end of the treatment at $15^{\circ} \mathrm{C}$ for 7 days, it elongated to about $1.4 \mathrm{~mm}$ (Fig. 3).

In conclusion, it is convenient for inducing chlorosis that the seedlings pretreated at $30^{\circ} \mathrm{C}$ for 3 or 4 days are treated at $15^{\circ} \mathrm{C}$ for 7 days.

\section{Effect of light intensity on chlorosis expression.}

Light is one of the indispensable factors for the chloropyll synthesis. In general, in natural condition of growing, chlorophyll accumulation is rapid at high temperatures under all conditions of light intensity. McWilliam and Naylor (1967) reported that under $16^{\circ} \mathrm{C}$ wheat produced the same amount of

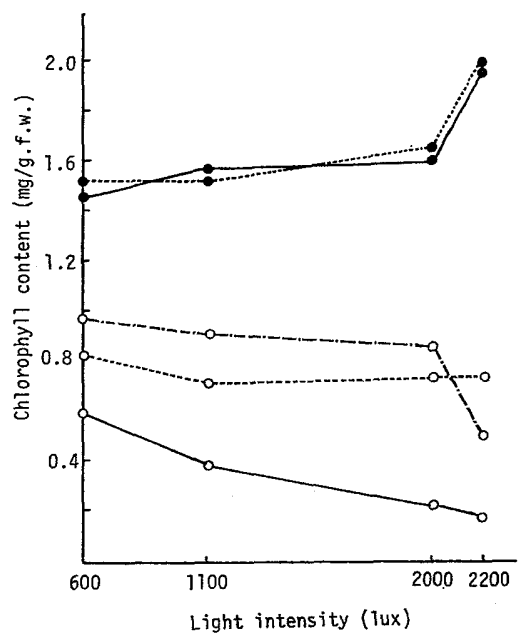

Fig. 4. Effect of light intensity on chlorosis. $\bigcirc-\bigcirc$, HO 1405 (IV);

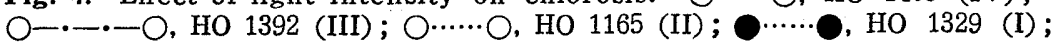
- $\mathrm{HO} 1250$ (O). 
chlorophyll at all light intensities but corn severely restricted chlorophyll accumulation at the higher light intensities.

In order to make clear the effect of light intensity on chlorosis, seedlings treated at $15^{\circ} \mathrm{C}$ in light for 7 days were transferred to $20^{\circ} \mathrm{C}$ under illumination at $600,1100,2000$ and 2200 lux. As shown in Fig. 4, types III and IV showed a decrease of chlorophyll contents when light intensity was increased. In type IV, variety HO 1405, at 600 lux, chlorophyll accumulation was almost 3-fold in comparison with that at 2200 lux. The patterns of chlorophyll decrease in respect to light intensity of types IV and III were not similar to each other. In type IV, chlorophyll content reduced straight from 600 to $2200 \mathrm{lux}$, whereas in type III, it was almost unchanged until 2000 lux and then reduced rapidly. Type II showed almost constant in chlorophyll content at any light intensity. Unlike the 3 types of chlorosis, types 0 and I took the advantage of high light intensity to accumulate chlorophyll.

\section{Chlorophyll recovery}

In some mutants sensitive to low temperature, when chlorosis once occurs resulting from the degeneration of chloroplasts and the photodestruction of chlorophyll, chlorophyll is never recovered (Walles, 1967). The virescent mutants in rice keep their white leaves until the senescence stage (Omura et al., 1977). To elucidate the behavior of chlorosis in rice in respect to this point, two varieties HO 1392 (type III) and HO 1405 (type IV) were investigated.

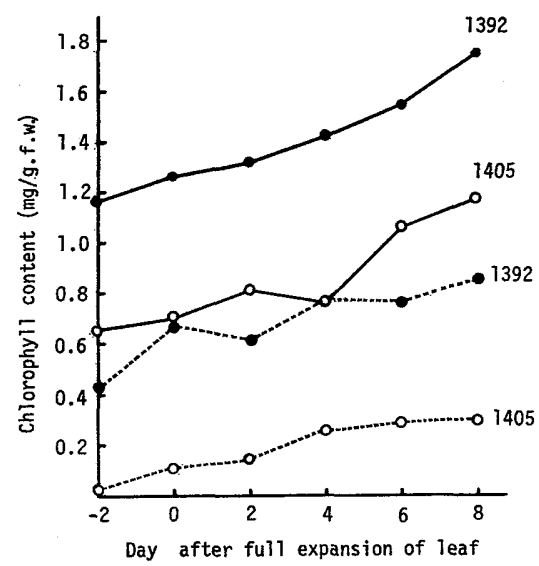

Fig. 5. Chlorophyll recovery. - at $25^{\circ} \mathrm{C} ; \cdots \cdots$, at $20^{\circ} \mathrm{C}$.

After chlorosis expressed following 7 days of $15^{\circ} \mathrm{C}$ treatment, chlorophyll was gradually recovered. The recovery process was similar in both varieties HO 1392 and HO 1405, starting from the lowermost part of the leaf then upwards along the main vascular bundles up to the leaf tip. As shown in Fig. 5, at $20^{\circ} \mathrm{C}$, the patterns of the chlorophyll recovery of both varieties were almost similar but variety HO 1405 completed its recovery process later than HO 1392 
due to its highest degree of chlorosis. The white portion of HO 1392 regained its whitish green while the lower part of the leaf turned in green after 6 days of recovery. The variety HO 1405 still kept the upper part of the third leaf in white even after 8 days of recovery. The same tendency was also seen at $25^{\circ} \mathrm{C}$ in the process of chlorophyll recovery. The chlorotic tissue of HO 1392 was almost disappeared after 6 days of transferring to $25^{\circ} \mathrm{C}$ for greening while it took 8 days to regain the pale green feature in the case of HO 1405. The same conclusion was reached when both of them were transferred to $30^{\circ} \mathrm{C}$ for greening. This means that the higher the temperature they are subjected to for greening, the more speedily they recover from chlorosis, and the higher the degree of chlorosis the more slowly they recover their chlorophyll. The recovery of chlorophyll after low temperature treatment raises some troubles in the classification of chlorosis types if the observation is not carried out in time.

\section{Relationship between second and third leaf in chlorosis expression}

Usually the third leaf expressed chlorosis, preceded by the chlorotic second leaf, but sometimes, even in the same variety, chlorosis expressed only the third leaf while the second leaf still kept in green. And even chlorosis appeared on the second leaf and after expressing its chlorosis the second leaf soon recovered its normal green feature from chlorosis before the third leaf fully emerged from the sheath of the second leaf. It seems that there might be a relation in chlorophyll formation between the second and the third leaf. Would the second green leaf transport a substance to the third leaf which promoted the normal chlorophyll formation in the third leaf? To make clear the point, after low temperature treatment, seedlings were transferred to $20^{\circ} \mathrm{C}$ for growing and when the second leaf fully expanded, they were cut off or covered by aluminum foil before it started to recover its chlorophyll. The covering by aluminum foil was a supplement measure to avoid the physiological disorder, if any, of the seedlings caused by the cutting of the second leaf. As shown in Fig. 6, there was no significant difference in chlorophyll contents

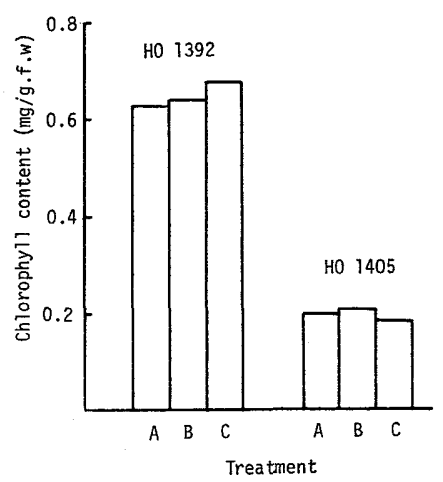

Fig. 6. Chlorophyll content of third leaf in relation to second leaf. A, second leaf cut off; $B$, second leaf covered; $C$, control. 
in both experiment measures comparing with the control. Thus, there might be no relation between the second and the third leaf in the chlorosis expression.

\section{Effect of iron on chlorosis expression}

As iron is an essential for the greening of plants, chlorosis usually appears on plants by the lack of iron. The symptom is so common that the term iron-chlorosis is used to describe it. Many evidences showed that chlorosis due to the deficiency of iron can be overcome by supplying iron to the medium or by spraying iron solution onto the foliage (Meelu et al., 1977; McDaniel and Dunphy, 1978). Furthermore, a large amount of information related to the temperature-induced chemical defects in higher plants has been reported (Ketellapper, 1963). To know whether the low temperature-induced chlorosis is influenced by iron or not, a series of iron concentration ranging from the amount in standard modified White's solution, $15 \mathrm{mg} / l$, to 8 -fold, 120 $\mathrm{mg} / l$, was tested. Seeds germinated at $30^{\circ} \mathrm{C}$ for 3 days were transferred to $15^{\circ} \mathrm{C}$ for 7 days then to $20^{\circ} \mathrm{C}$ for growing. As shown in Fig. 7, low temperature-induced chlorosis showed independent to the effect of iron. None of the 4 types of chlorosis along with type 0 expressed any remarkable change in chlorophyll content even at high doses of iron concentration. The phenotypic appearance in white tip and albino-like remained unchanged at every concentration of iron in the medium.

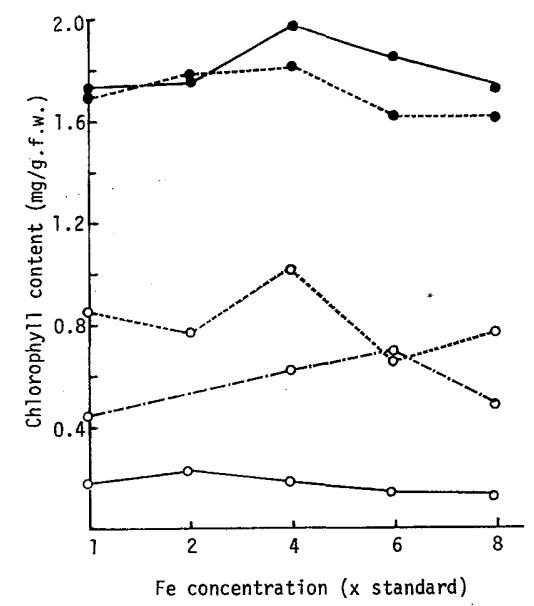

Fig. 7. Effect of iron on chlorophyll content. $\bigcirc-0$, HO 1405 (IV)

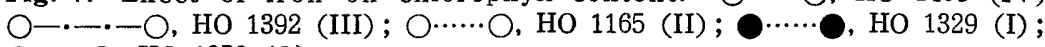
- HO 1250 (O).

\section{Effect of nitrogen on chlorosis expression}

Nitrogen is the most important nutrient for higher plants. Usually, the increase of nitrogen in the medium leads to the increase of chlorophyll content in leaves, and the lack of nitrogen induces the chlorotic symptom on the leaf and reduces the growth rate. But Omura et al. (1977) reported a special 
case of virescent mutants in rice which behaved quite differently in response to nitrogen. Those virescent mutants showed a decrease of their chlorophyll contents with the increase of nitrogen in the media. May the low temperature-induced chlorosis be influenced by nitrogen? To elucidate the question, six levels of nitrogen concentrations, nitrogen-free, 1-, 2-, 4-, 6- and 8-fold of that of the modified White's solution, were used for testing. Seeds germinated after 3 days at $30^{\circ} \mathrm{C}$ were transferred to $15^{\circ} \mathrm{C}$ for 7 days then to $20^{\circ} \mathrm{C}$ for growing. No visual difference in the third leaves fully expanded was revealed among the treatments in each of types II, III, and IV, whereas types I and 0 distinctly turned in dark green at high doses of nitrogen. The chlorophyll contents of type IV, as shown in Fig. 8, kept unchanged at all nitrogen concentrations. There was a small increase in chlorophyll content in the case of type III at 6 and 8 times of nitrogen but the difference was non significant and it might be due to the rapid recovery of chlorophyll at the base of the third leaf blade. Chlorophyll contents of types I and 0 sharply increased when the concentration of nitrogen doubled the standard. Without the bleaching of chlorophyll from the beginning, types I and 0 took the advantage of nitrogen in their biochemical activities in the chlorophyll synthesis. Their patterns of chlorophyll increase, however, showed a little difference. Type 0 even at the highest dose of nitrogen did not show any change in chlorophyll content whereas type I sharply decreased its chlorophyll at the dose of 8-fold of the standard.

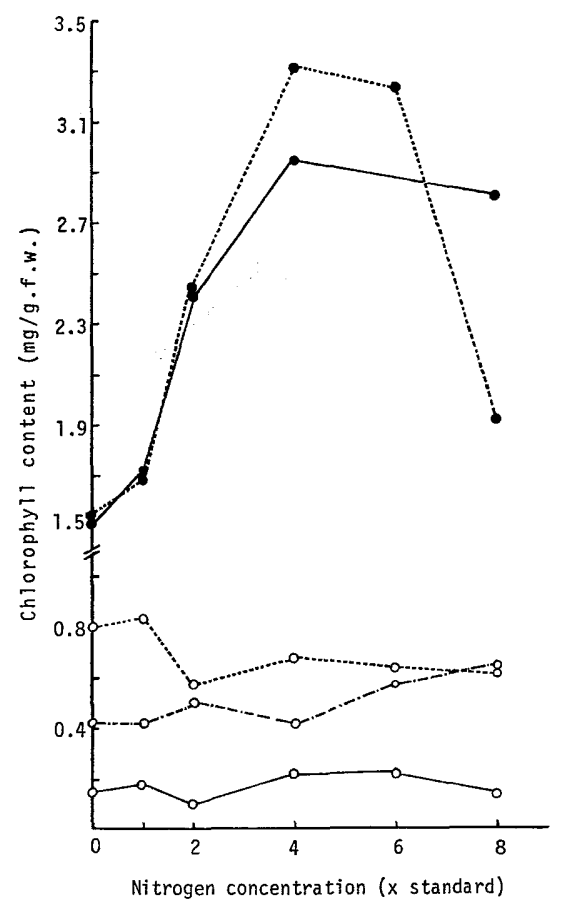

Fig. 8. Effect of nitrogen on chlorophyll content. Symbols as in Fig. 7. 


\section{DISCUSSION}

Five types of chlorosis expressed at $17^{\circ} \mathrm{C}$ were reported in the previous paper. At this temperature, there was sometimes an overlap between type 0 and type I as well as between type III and type IV in phenotypic appearance and in chlorophyll content. Fortunately, the former behaved differently at $15^{\circ} \mathrm{C}$ and the latter at $20^{\circ} \mathrm{C}$. At $15^{\circ} \mathrm{C}$, type I expressed its chlorosis in white while type 0 kept unchanged its phenotype in green or sightly turned in pale green. At $20^{\circ} \mathrm{C}$, only type IV still remained its chlorotic feature while type III turned in green. Therefore, $15^{\circ} \mathrm{C}$ can be considered as the critical temperature of type $\mathrm{I}$, and $20^{\circ} \mathrm{C}$ of type IV (Table 1). The low temperature effect on the chlorosis expression is quantitative, that means when affected by certain quantity of low temperature, young seedlings start to express chlorosis. Below that quantity, chlorosis does not express and an overdose of that quantity leads to an overlap of different types of chlorosis into albino-like leaf, and the classification in that case become unable. The least quantity of low temperature indispensable to chlorosis expression varies according to chlorosis types. At $15^{\circ} \mathrm{C}$, the least durations of low temperature treatment enough to induce chlorosis were 5 and 3 days for types II and III, respectively. Type I expresses chlorosis under continuous treatment at $15^{\circ} \mathrm{C}$ whereas type IV expresses chlorosis even at $20^{\circ} \mathrm{C}$. The least duration of low temperature treatment is not enough to classify chlorosis types due to their ressemblance in appearance. Chlorosis types become distinct when $15^{\circ} \mathrm{C}$ treatment is carried out for about 7 days then transferred to $20^{\circ} \mathrm{C}$ for growing and their appearances in such conditions are similar to those under continuous $17^{\circ} \mathrm{C}$ treatment, respectively. Because of the convenience and time-saving, the method of $15^{\circ} \mathrm{C}$ treatment for 7 days is preferable in chlorosis induction (Table 2).

Low temperature affects most effectively at a certain period of the leaf development. If the leaf is not subjected to low temperature at this stage of development, chlorosis does not express its typical phenotype, and consequently, the distinction of chlorosis types becomes difficult. In the case of type IV (HO 1405), the stage most sensitive to low temperature coincides with the stage when the differentiation of the third leaf just begins, about $0.2-0.3 \mathrm{~mm}$ in length. It takes about 3 or 4 days to reach this stage when seeds germinate at $30^{\circ} \mathrm{C}$ in dark condition. After the treatment at $15^{\circ} \mathrm{C}$ for 7 days, the length of the third leaf reaches about $1.4 \mathrm{~mm}$. Thus, it is concluded that the leaf development stage most sensitive to low temperature is in the range from 0.2 to $1.4 \mathrm{~mm}$ of the third leaf length (Figs. 2 and 3). This temperature sensitive stage of chlorosis is different from that of virescent mutants reported by Omura et al. (1977). The sensitive stage of virescent mutants appears to be much later, at the stage when the length of the third leaf reaches about $14.4 \mathrm{~mm}$.

The low temperature-induced chlorosis in rice showed a local effect as Lubimenko (1927) stated. The second leaf usually showed non-unique in growth rate, therefore, sometimes some appear in normal appearance probably due to the shift of the sensitive stage from the low temperature effect. 
Although the second leaf turns in green, there is no transport of substances from the green leaves to promote the normal chlorophyll formation in the third leaf (Fig. 6). This is quite different from the case of a mutant corn in which Millerd et al. (1969) assumed that there was a transport of substance or subtances which promoted the normal chloroplast development in the newly differentiated cells of the bundle sheath and neighboring mesophyll cells after transferred to low temperature.

High light intensities cause photobleaching of chlorophyll (Smith et al., 1959). Chlorosis types III and IV were highly bleached in hight intensities whereas type II kept almost constant in their chlorophyll content (Fig. 4). The degree of bleaching is very helpfull in the classification of chlorosis. Although bleaching occurred, all types of chlorosis recovered their chlorophyll when transferred to high temperature (Fig. 5). This indicates that despite of being bleached there may be no damage of the mechanism leading to chlorophyll accumulation process in contrast with many cases of mutants. In the case of virescent mutants in rice sensitive to low temperature, chloroplasts remained the stage of proplastids and contained no ribosomes (Omura et al., 1977). In barley mutants, bleaching leaves was the result of the degeneration and deformation of plastids which become amoebic in shape, although grana may persist for some time (Walles, 1967). Another case of bleaching caused by the error in aggregation of the lamellar discs in the chloroplast was found also in barley mutants by Wettstein (1960). In all those cases, chlorophyll could not recover due to the damage or the defects of the chloroplast structure. Bleaching in this case of chlorosis, different from those mutants, may be due to the stagnation of chloroplast development at a certain stage under low temperature condition so that chlorophyll just formed cannot complex with the chloroplast lamellae which appears to protect it from rapid photodestruction as stated by McWilliam and Naylor (1967). On the effect of low temperature on the development of lamellar system in chloroplasts in maize, Klein (1960) also reported the abnormal formation of ring structures of lamellae under $3^{\circ} \mathrm{C}$ condition. In the case of chlorosis, when temperature raises, it is suggested that the chloroplast continues to develop normally so that chlorophyll is possible to accumulate resulting in the recovery of chlorophyll (Fig. 5). More information on chloroplast formation is still awaiting.

On the nutrients affecting the chlorosis expression, Bogorad et al. (1959) observed abnormal plastid structures in electron photomicrographs of iron deficient maize plants and stated that chlorosis caused by iron deficiency may be due to a requirement for the iron in the structural development of chloroplasts. The iron requirement for chlorophyll synthesis was assignable to the step in porphyrin synthesis at which coproporphyrinogen is converted to protoporphyrin (Price, 1970 a). In iron chlorosis, iron supply is not enough to complete the incorporation of $\mathrm{Fe}^{++}$into protoporphyrin leading to the ineffectiveness of the chlorophyll synthesis. The defect can be overcome by an extra supply of iron whether by direct spraying onto foliage as in chlorotic paddy nurseries (Meelu et al., 1977), in pineapple (Price, $1970 \mathrm{~b}$ ) or by adding in medium as in chlorosis of oat (McDaniel and Dunphy, 1978). 
An extra supply of iron did not show any fluctuation in chlorophyll content in all types of chlorosis (Fig. 7). This indicates that low temperatureinduced chlorosis performs quite differently from iron chlorosis which requires the incorporation of $\mathrm{Fe}$ into the porphyrin ring necessary for the process of chlorophyll synthesis. Thus, it is likely that the block of chlorophyll formation in the case of low temperature-induced chlorosis does not appear at the step of porphyrin synthesis but at later stage.

The response to nitrogen in the case low temperature-induced chlorosis in rice is also not similar to the general concept on which based the fact that nitrogen is essential for the greening of plant. The virescent mutants in rice showed a decrease of chlorophyll content following the increase of nitrogen nutrient (Omura et al., 1977). The response of chlorosis to nitrogen nutrient is different from the cases above mentioned. Without bleaching of chlorophyll as in types 0 and I, nitrogen makes an increase of chlorophyll yield but contrarily, in case of bleaching as in types II, III and IV, it neither raises nor lessens the chlorophyll contents of these types (Fig. 8). It is not known, however, whether nitrogen really induced the chlorophyll formation but the newly formed chlorophyll failed to be complexed with the chloroplast lamellae and, as result, suffered photodestruction or, in fact, completely did not play any role in the chlorophyll formation in chlorosis expressed under low temperature condition in rice. Further study on the chloroplast development under low temperature is carrying out.

The low temperature-induced chlorosis in rice may be of critical importance in adaptation of the species to the climatic condition. The non-destruction of the functional photosynthetic system is indispensable for survival.

\section{REFERENCES}

Bogorad, L., G. Pires, H. Swift and W. V. McIlrath 1959 The structure of chloroplasts in leaf tissue of iron deficient Xanthium. Brookhaven Symp., 11: 132-136

Hitaka, N. 1976 Chlorosis of rice seedlings in mechanized transplanting. Japan. Agr. Res. Quart., 10: 109-113

Ketellapper, H. J. 1963 Temperature induced chemical defects in higher plant. Plant. Physioi., 38: 175-179

Klein, S. 1960 The effect of low temperature on the development of the lamellar system in chloroplasts. J. Biophys. Biochem. Cytol., 8: 529-538

Lubimenko, V. 1927 Traité de Botanique générale. Gauthier-Villars et Cie. Paris. Rev. Genet. Bot., 40: 1-115

McDaniel, M. E. and D. J. Dunphy 1978 Differential iron chlorosis of oat cultivars. Crop Sci., $18: 136-138$

McKinney, G. 1941 Absorption of light by chlorophyll solution. J. Biol. Chem., 140: 315322

McWilliam, J. R. and A. W. Naylor 1967 Temperature and plant adaptation. I. Interaction of temperature and light in the synthesis of chlorophyll in corn. Plant Physiol., 42: 1711-1715

Meelu, O. P., S. Saggar and G. S. Sekhon 1977 Iron chlorosis in paddy nurseries. Int. Rice Res. Newsletter, 2 : 11 
Millerd, A. and J. R. Williams 1968 Studies on a maize mutant sensitive to low temperature. I. Influence of temperature and light on the production of chloroplast pigments. Plant Physiol., 43: 1967-1972

Millerd, A., D. J. Goodchild and D. Spencer 1969 Studies on a maize mutant sensitive to low temperature II. Chloroplast structure, development and physiology. Plant Physiol., 44: $567-583$

Omura, T. and P. V. Chuong 1979 Studies on the chlorosis expressed under low temperature condition in rice, Oryza sativa L. I. Classification and relationships with other characters. J. Fac. Agr., Kyushu Univ., 23: 175-182

Omura, T., H. Satoh, I. Aiga and N. Nagao 1977 Studies on the character manifestation in chlorophyll mutants in rice 1 . Virescent mutants sensitive to low temperature. $J$. Fac. Agr., Kyushu Univ., 21 : 129-140

Price, C. A. 1970 a Chemical transformation in green plants. In "Molecular Approaches to Plant Physiology", McGraw Hill, Newyork, pp. 65-69

Price, C. A. $1970 \mathrm{~b}$ Inorganic nutrition. In "Molecular Approaches to Plant Physiology", McGraw Hill, Newyork, pp. 244-249

Smith, J. H. C., L. J. Durham and C. F. Wurster 1959 Formation and bleaching of chlorophyll in albino corn seedlings. Plant Physiol., 34: 340-345

Walles, B, 1967 Use of biochemical mutants in analysis of chloroplast morphogenesis in biochemical of chloroplast. Vol. 2, ed. by J. W. Goodwin, Academic Press, London and New York pp. 633-653

Wettstein D. von. 1960 Multiple allelism in induced chlorophyll mutants II. Error in the aggression of the lamellar discs in the chloroplast. Hereditas, 46: 700-708 